\title{
Quality Enhancement of Environmental Aesthetics Experience Through Ecological Assessment Case Study: River of Darabad Valley, Tehran, Iran
}

\author{
ALI REZA SADEGHI', MOHAMMAD REZA POURJAFAR ${ }^{2}$, \\ ALI AKBAR TAGHVAEE ${ }^{3}$ and PARVIZ AZADFALLAH ${ }^{4}$ \\ ${ }^{1} \mathrm{PhD}$ Candidate of Urban Design at Art and Architecture Faculty of Tarbiat Modares University, Tehran. \\ ${ }^{2}$ Full Professor and Dean of the Department of Urban Design \& Planning, \\ Faculty of Art and Architecture at Tarbiat Modares University, Tehran. \\ ${ }^{3}$ Associate Professor and Dean of Art and Architecture Faculty at Tarbiat Modares University, Tehran. \\ ${ }^{4}$ Associate Professor and Dean of the Department of Psychology, Faculty of Humanities \\ at Tarbiat Modares University, Tehran.
}

http://dx.doi.org/10.12944/CWE.9.3.39

(Received: July 31, 2014; Accepted: September 05, 2014)

\begin{abstract}
In this article by reviewing the environmental aesthetics experience, natural townscape, and ecological assessment related concepts, ecological assessment is known as a process that pave the way for achieving a positive (pleasant) experience of natural aesthetics in natural townscape. In fact, it seems that ecological assessment and evaluation of the natural context should be the fundamental part in the process of urban design of large scale projects, which are developed to improve the quality of environment aesthetics experience. Since, ecological assessment of the context contributes to analysis and evaluation of those elements and aspects of the environment that provide human with better concentration to obtain more pleasant aesthetic experience. In this study, by performing ecological study, analysis, and assessment of the natural context of Darabad valley's river, as one of the central urban and natural landscapes in Tehran, approaches and policies that are related to environmental aesthetics in this natural townscape are developed. These approaches and policies highlight better rehabilitation and restoration of the context of valley's river, as a human real and public space; preservation, improvement, and understanding of ecological and biological resources; and increase of visual quality and enrichment of views and vistas in the river's bed. The present analytical-descriptive case study has used several research methods such as literature, references, and visual documents review, and observation and simulation in the context of library and field investigations.
\end{abstract}

Key word: Environmental Aesthetics, Aesthetic Experience, Natural Townscape, Ecological Assessment, River of Darabad Valley.

\section{INTRODUCTION}

In half of the twentieth century, environmental aesthetics related theoretical subjects and understanding the beauty of natural and artificial environments around human being were addressed more than ever. Paying attention to this approach was a response to analytical aesthetic attitude towards understanding and perceptualization of the environment which argued that aesthetics and understanding natural and artificial environment around men are unimportant, subjective, and non-aesthetics due to the defects and failures of environment and nature and the way they are understood. In contrast, environmental aesthetics theorists such as Hepburn and Aldo Leopold believed that natural and human-made environments surrounding men are indeed resources that can be used to obtain a different aesthetics experience which is potentially rich and valuable. 
Since environment is in no way limited to concepts such as artistic-historical traditions and artisticcritical theories. Therefore, it allows human to obtain infinite, pleasant, and creative understanding of it. It is the understanding that follows an evolutionary shift from superficial aesthetics experience to a deep and serious one. Therefore, environmental aesthetics and the experience from it are formed based on two main bases. First, differences between art and environment with respect to the resources available for achieving aesthetics understanding and experience. Second, the way natural and human-made environments, which with respect to analytical aesthetics was bounded by old paradigm of objective contemplation in sensory and superficial characteristics, are understood. In fact, environmental aesthetics paved the way for obtaining aesthetic experience from the environment by highlighting infinity of natural and human-made environments and the importance of understanding them by human. An experience that can be rich and valuable in emotional and cognitive respects.

Although in texts of 1960 s there was an increasing growth in scientific researches in environmental aesthetics, it seems that there was not enough connection between research and practice back then and, as a result, there is still some attempts to set a practical framework in this area. In 1978 Chalmers presented a new typology of research in environmental aesthetics, underlining tentative and indistinct differences between basic and practical researchers as well as employing quantitative and non-quantitative methods ${ }^{1}$. In the beginning of 1990s there were other attempts to structuralize the environment's aesthetics. Tuan's research ${ }^{2}$ as usual gives no structure. His work is special and cannot be extended. Also Berleant's attempt $^{3}$ is, similar to Tuan's work, widespread, philosophical, and infrastructural. Bourassa's work ${ }^{4}$ has quite easily been structuralized into biological, cultural, and personal units. Although Nasar ${ }^{5}$ does not give an integrated and comprehensive structure, his research is logically divided into three parts of theory, research, and uses. Punter in 1982 by employing a philosophical approach determined three paradigms, presenting a material vision for environmental aesthetics ${ }^{6}$. Zube, Sell, and Taylor by using a theoretical approach based on the accurate quantitative analysis of the existing literature, have presented some paradigms and have provided a pattern of understanding the scene and the environment for environmental aesthetics ${ }^{7}$. Also Porteous in 1996 by using a problemcentered approach suggested four paradigms for environmental aesthetics, bringing up their interaction in terms of producing and using the theory ${ }^{8}$.

However, in recent years, urbanization has always experienced ever increasing growth. In that, the last decades of the past century witnessed $100 \%$ increase in urban population, comprising about $45 \%$ of the world population. Besides advantages such as accessibility to clean water, hygiene, and so like, the negative effects of urbanization on environment, especially degradation and pollution of urban environment, cannot be ignored. These negative effects have faced the process of environmental aesthetics experience in human with problem. In fact, due the reduction of ecologically valuable natural landscapes and regions inside urban areas, which taken as important parts of natural townscape, several environmental issues have been emerged. To decrease environmental issues of today's cities and reduce negative impacts of urbanization on urban environment, stronger presence of nature and natural elements in townscape (as the environment and container of human activities) and enrichment of experiences in understanding natural elements of natural townscape are necessary for citizens. Since, townscape is comprised of natural and human-made environments which always provide the ground for human activities. Therefore, human activities are affecting and affected by natural and man-made townscape. There are two standpoints with respect to human's relationship with natural townscape. In one of them, human always ignored his evolutionary history, the way cities formed, and the necessity for maintaining natural townscape. In contrast, from the other perspective, human is aware of his past and unity with everything and all living creatures. Based on the latter, human wisely respect townscape and seeks his creative role in this context. With respect to the second point of view, ecology of natural townscape is the study and use of information related to natural patterns and processes of the context and the way it is connected to material world and living creatures (human and other living organisms) in different scales. In fact, 
the main objective of ecological assessment of natural context is to know how the ecosystem acts and how the present and future dynamicity and changes affect it. It seems that appropriate use of this type of assessment will result in enhancement of experience of environmental perception, provision of opportunity for better interaction of human with natural townscapes (regarding capabilities and capacities of the environment), and achievement of aesthetic objectives of the environment. In effect, analysis and assessment of ecology of natural contexts through understanding, investigation, and analysis of mosaic patterns and structures, allow for the experience of aesthetics' values of townscapes, which finally contribute to preservation of these landscapes for future generations. (Fig. 1)

With regard to what was said, the main goal of this article is present a practical framework and strategies for enhancement of experience of environmental aesthetics in natural townscape. This framework and strategies with emphasis on ecological assessment can be increase connection between practice and basic in environmental aesthetics.

\section{MATERIALS AND METHODS}

With no doubt one of the major signs of aesthetics appears in human's surroundings (Fig. 2). Envrionmental aesthetics is different from the aesthetism, even though there are some connections in between. Yet environmental aesthetism is experiencing the cognitive and sensual traits of the environment by means of all senses. In this point of view, aesthteism in its broad sense deals with the evaluations and methods of discerning and understanding the environment as well as the individual's position in it. This is because human is not separated from the environment, being a part of a whole with its related components. In fact the experience of environmental aesthetics is of a completely-cognitive nature, though some non-cognitive factors complement and affect it. This gives environmental aesthetics the right to be considered as an important factor of human life. As a matter of fact environmental aesthetics is the multi-sensual and comprehensive connection with the environment, of which human is one of the natural components. When aesthetic or sublime senses are great, the experience of environmental aesthetics can become very strong, with valuable mental stimulations. Environmental aesthetics can be a mundane and ordinary pleasure around us, the highest rate of which is in an environment with affinity, complexity, and ambiguity (9). In fact the experience of environmental aesthetics has a general characteristic, among all people and in all times it requires focus on some aspects of the surrounding environment. In this process, the longer and deeper is the focus, the better and more constant becomes its aesthetic quality. Although this aesthetic experience can be positive (pleasant) or negative (impleasant), this article focuses on the former. The main characteristic of positive aesthetic experience is emphasis on an experience of the environment, in which its receiver is pleased with its state as well as the senses and influences, brought to him from that understanding, and can control or change it the way he likes, or perpetuate it without any changes, giving it a positive environmental aesthetics response to the environment. In fact positive environmental aesthetic experience is emphasis on environmental information, their reception through the senses, and getting pleasure from the reflection of such information in the mind. It is the result of a kind of active interaction between the environment's realization and superficial traits as well as human's thoughts and mental images, giving value and meaning to his life. Since human's surrounding in the most general view is divided to natural and artificial environments, such type of aesthetics is divided into aesthetics of artificial (processes and ways of sensing and understanding artificial environments and explaning the individual's position in them) and natural environment (processes and ways of sensing and understanding natural environments and explaning the individual's position in them).

According to what was aforementioned, it seems that the framework of environmental aesthetics is the result of the multilateral, mutual, and permanent interaction between human and environment and, consequently, the fruit of mutual reaction of human's environment's aesthetics with his aesthetic responses to it. This framework has four dimensions, aspect, or major subgroup. This first involves taking pleasure from scenes along with formal aesthetic senses of urban landscape (having to do with the five senses). The second 
dimension is attachment, dependence, and love (feeling). The third dimension is about spirituality and respect for the environment (experience and fascination). And finally the fourth dimension is about the necessity following moral principles when facing the environment as well as responsibility to natural and artificial environment around human kind (thought and mine) (fig. 3). However, certainly one of the most important embodiments of environment (whether natural or man-made) in human's residences is urban landscape and bringing up environmental aesthetics in urban landscape, particularly in terms of natural urban landscape and its elements causes aesthetic values move from art galleries and architectural single buildings to natural forms and large-scale artificial environments. In urban landscape, visual elements contain a set of elements which in different contexts show the capabilities of an area's landscape, making the set's landscape legible, improving its quality, and giving it a special position in people's mental map in order to help orient and direct the set itself ${ }^{10}$. These elements include: signs and symbols, environmental qualities, visual qualities, gateways, public realms and spaces, edges, and directions. Fig. 4 presents the elements of natural urban landscape along with the view points on human's relation with natural urban landscape itself. Here environmental qualities mean special natural traits such as hills, elevations, natural slope of the earth, trees and ecological areas, streams and rivers, valleys, landscapes, plantation, and specific topography, characteristics which are called natural urban landscape in this article. In fact for a comfortable life, mankind needs a pleasant urban landscape. Valleys are called as one of the main elements of natural urban landscape. Combination of natural elements of water, soil, rocks, and plants with each other and in various artistic forms in valleys (especially in the valleys of Tehran) reminds of the manifestation of basic nature, giving a special calmness to human. Table 1 shows the role of valleys in the formation of urban landscape, substantial necessities in these elements, and the most important opportunities and threats, facing this element of natural landscape in details. It seems that an ecological approach in planning and designing the context, saving and regenerating natural systems, emphasizing the citizens' education, and achieving life patterns in the nature strengthens and organizes humans' connection with the nature and qualitatively improves the experience of environmental aesthetics of these main elements in natural landscape. Accordingly in order to strength this connection, the ecology of natural urban landscape along with the analysis of valley beds' ecology and that of its surrounding plays a significant role.

\section{Ecological Analysis of Natural Urban Landscape}

It is said that the structure of urban landscape is the result of a correlated distribution of the paths and corridors in the city's geodesic context, where the characteristics of such natural components determine its structural status ${ }^{11}$. Therefore the ecology of natural urban landscape is the study and use of the information, related to its patterns and processes as well as how they overlap with the ground's form (here meaning urban landscape) in different scales ${ }^{9}$. These natural patterns in urban landscape may involve topography, ground's covering and quality, surface and underground waterways, ravines and edges of streams and rivers, soil quality, steep slopes, forests and woods, types of flora and fauna, climate kind and weather, etc. There are various methods to recognize and analyze natural patterns since environmental conditions always determine the methodology and one cannot pre-design a specific methodology to carry out a particular study without primary analyses of the studied region. Based on the grand scale (regional and suburban) of most methods for evaluating natural patterns it seems that ecological evaluation method, explained below, is an appropriate one to evaluate natural urban landscape, the suitable use of which will improve the experience of understanding the environment and fulfill environmental aesthetic goals, as the major part of ecological studies involve analyzing ecosystems' structure. It can be said that the structure of each ecosystem pertains to the organization of its parts as well as related systems. Natural and artificial patches along with corridors and networks, connecting them, form the main structure of each ecosystem. Structure is a unifying concept, being the result of all happenings in terms of layout, direction, mass and scale, enclosure, and connections and links. Moreover unification in decisions about artificial environment will create an integrated structure. As a matter of fact, structure exists where all dynamic aspects are placed near each other which show 
the change and dynamism of structure in time. Parts' layout pattern (such as vegetation and even accessibilities) shape each system's structure, organizing its space and mass ${ }^{12}$. Table 2 defines the main elements and components of ecological evaluation of natural urban landscape, categorizing their concepts. These elements and components in natural urban landscape can be man-made, organic, or a combination of both. After identifying the main components of ecological evaluation, Darabad (in Tehran) valley will be evaluated ecologically so that with the results from this evaluation, necessary groundwork for presenting approaches and quality improvement policies of environmental aesthetics in natural urban landscape is prepared.

Darabad neighborhood in recent decades has experienced a chief skeletal, social, cultural, and practical evolution process, turning from an old village to part of the structure of Tehran metropolis. Unfortunately in this process, due to lack of plans the changes in this old neighborhood have occurred automatically. Meanwhile Darabad valley is the main factor of Darabad development, having linked the natural rural landscape of the past with the pure natural as well as the natural urban landscape of the present. Natural landscape of Darabad valley, among other valleys in Tehran, is in relatively better condition and have been assaulted less. More pure green spaces cane be found there. Chief elements of Darabad valley context involve river spine, heights, mountain, vale, Darabad hills and its related natural patches, riverside vegetation, pure natural and natural urban landscape around the river, rural and urban residential center, Masih Daneshvari Hospital, Dane Nezami wide area, Pur Ebtehaj Street, empty and untouched spaces, gardens, and old green patches (Pic. 1).

\section{DISCUSSION}

\section{Ecological Evaluation of Darabad Valley, Tehran} Mosaic evaluation of this natural urban landscape's context show that Darabad valley

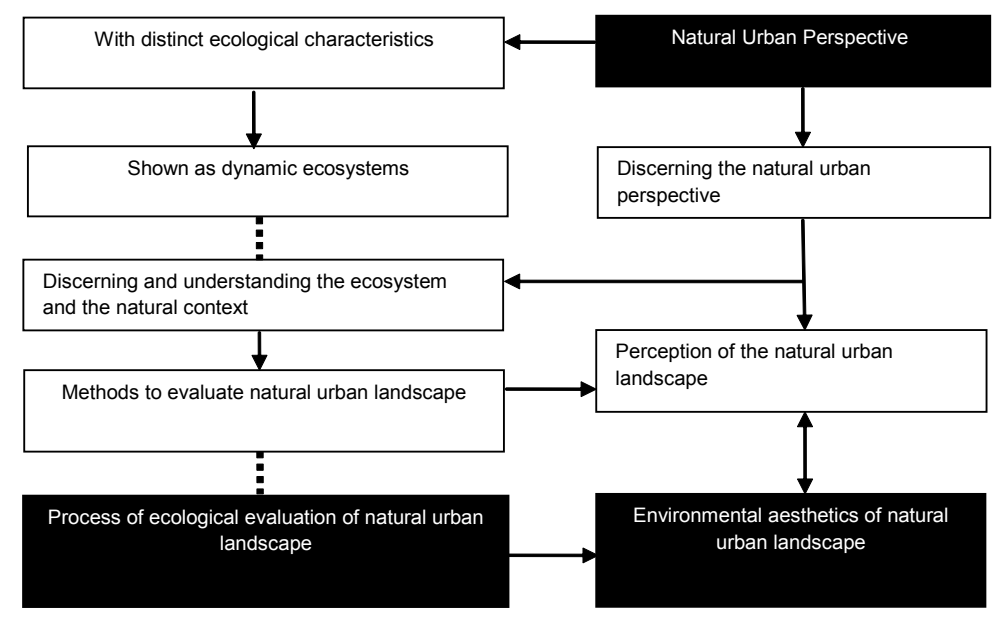

Fig. 1: Explanation of the connection between urban natural perspective, environmental aesthetics, and the process of ecological analysis. Source: the authors

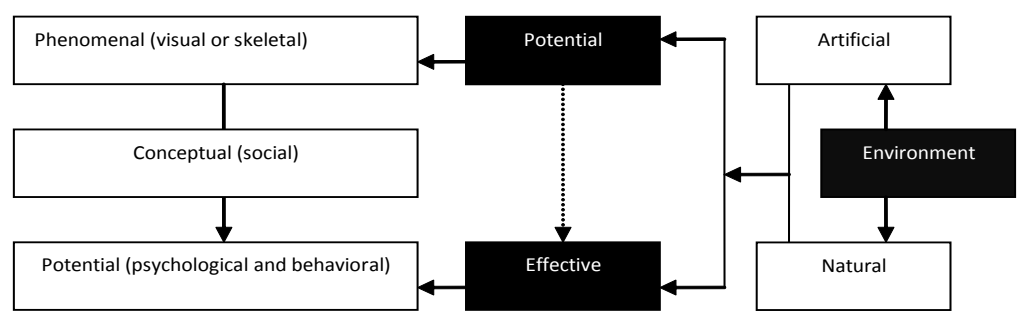

Fig. 2: Categorization of environment types. Source: the authors 
context, which has a collared pattern of open spaces and enclosures that are interinconnected with corridors and paths, is divided to three main patches of mountainous/natural, half-urban/natural, and urban/natural. It is in the context of these 3 major patches that secondary patches, such as organic residential tissues and newly-made residential complexes, gardens and green spaces, riverside vegetation and mountain open green spaces, spaces with healthcare and military uses, are interconnected with routes, pavements, and roads on the axis of Darabad River as the main passage. Analysis of landscape structure in large scale of the area of study and based on geomorphologic characteristics show that in this context there three main categories of mountain, valley, and urbanized landscape. In this division, mountain landscape contain mountains, canyons, Darabad River, rock outcrops, natural attractios such as waterfalls, caves, springs, transient seasonal patches, and diversity of

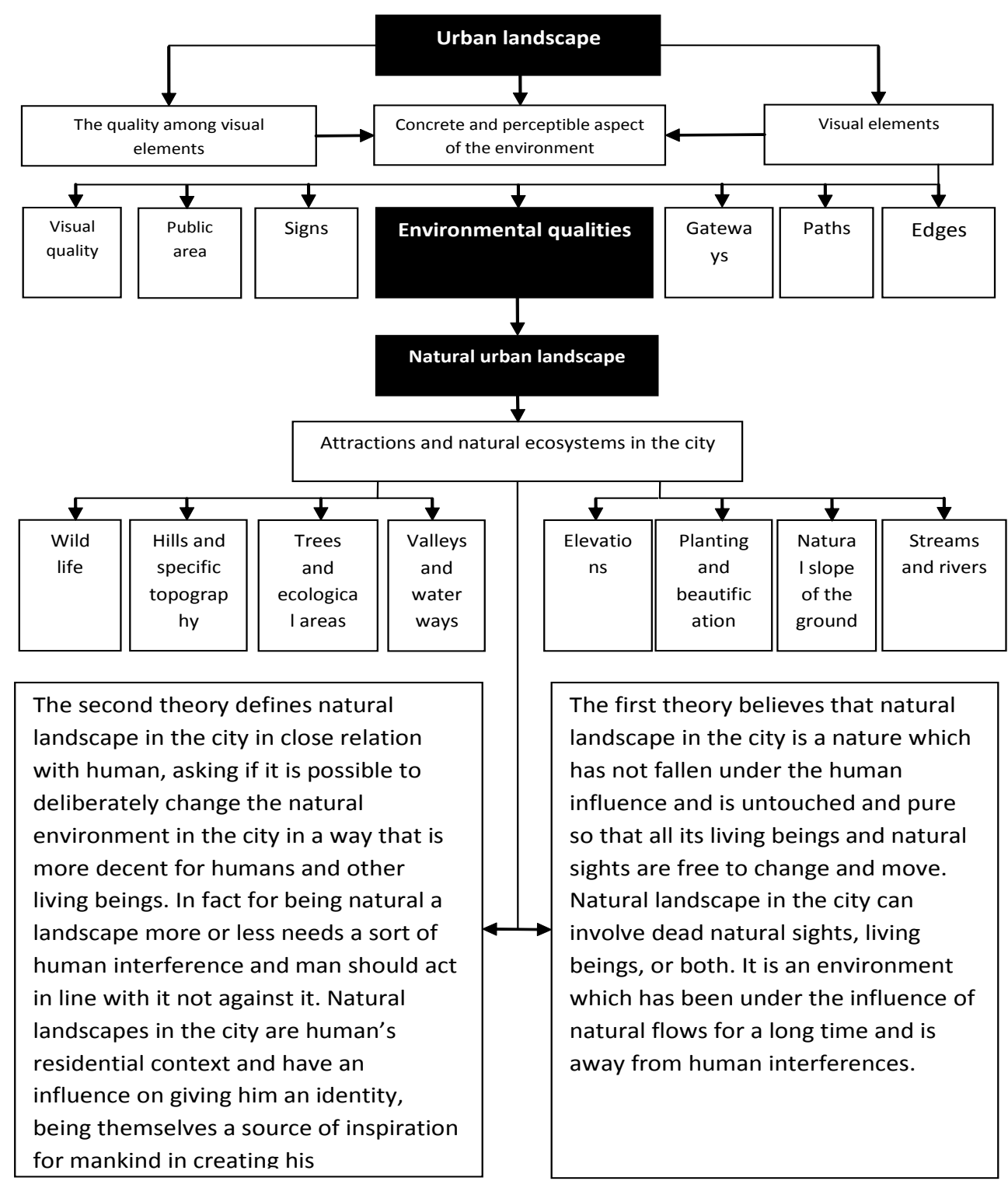

Fig. 3: The elements of natural urban landscape and different perspectives to it. Source: the authors 
ground shape. Valley landscape is made of rivers and riverside vegetation. In accordance with the ground shape, valley height and body, and the rate of its naturalness, valley landscape is divided into three areas, which are high, fairly-high, and low valleys. Yet in urbanized type of landscape presence of villas and garden houses on mountain slopes shows the change of mountain and valley landscapes to the urban one. Decrease of green space and transformation of gardens and villas to apartments and imbalance and disorder of skyline demonstrates a fully urban landscape. Table 3 analyzes the form of these patches in the natural urban landscape mosaic of Darabad valley. (Table 3)

Darabad valley in all parts (mountainous, natural, half-urban, and urban) has fine vegetation. In mountain-natural part, the set of trees with riverside shrubs (with valuable willow, spruce, plane, ailanthus, and ash trees) has remained unchanged. Planted vegetation, various crops, and existing gardens (with lasting trees such as planes,

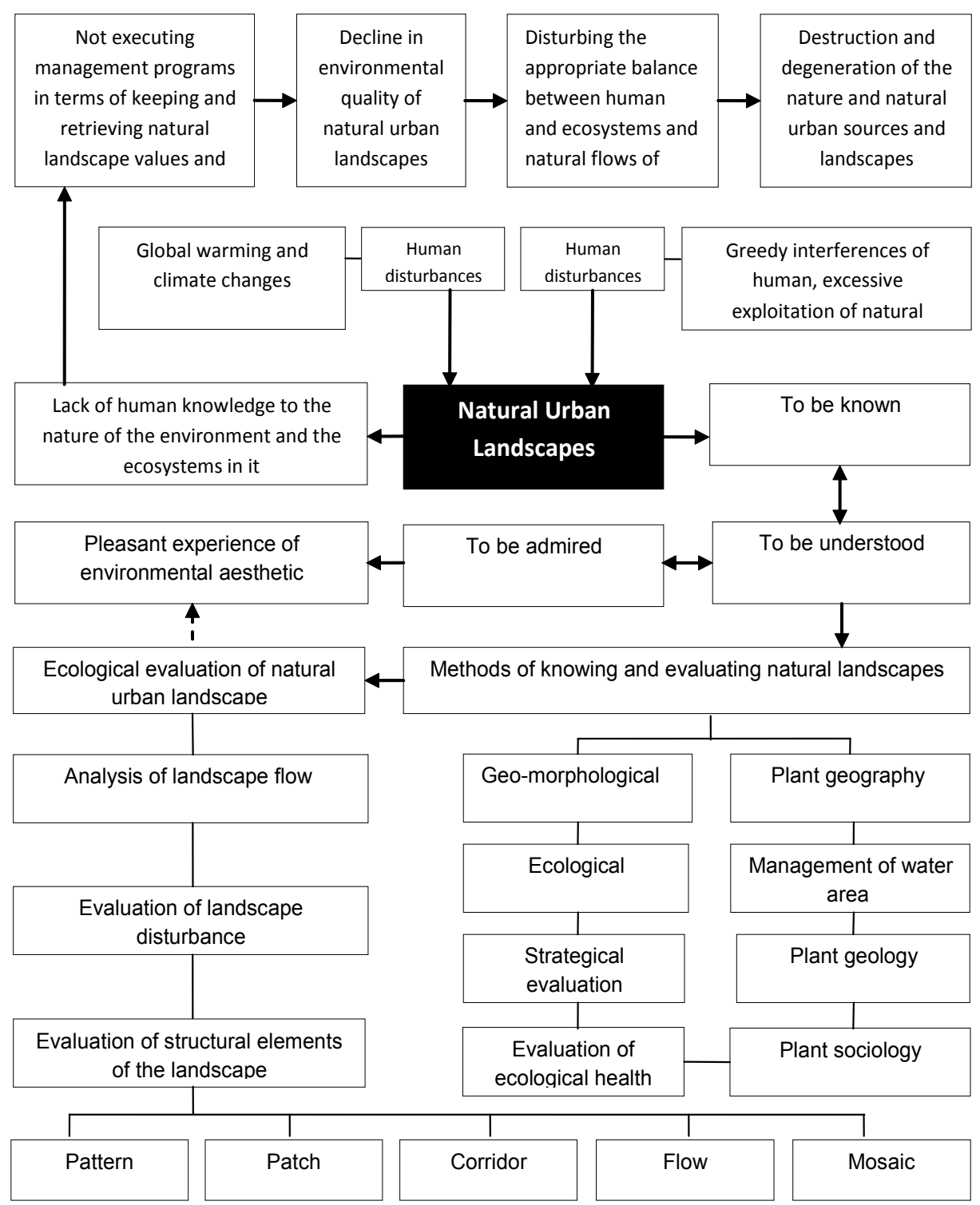

Fig. 4: Ecological evaluation as a Method to Focus on the Environment, Know the Ecological Layers of the Natural Urban Landscape, and Facilitate the Pleasant Experience of Environmental Aesthetics. Source: the authors 
walnuts, mulberries, figs, and pines) have created an appropriate foreground in order to develop the vegetations. As a matter of fact, in the analysis of landscape structure, in terms of vegetation type and based on parameters of slope, direction, soil, and ground shape of the studied area it can be divided into three pieces of natural homogenous, half-natural homogenous, and fully-disturbed homogenous. A natural homogenous piece contains riverside communities, crop and shrub vegetation on the slopes, and trees alongside the river. It has many rock outcrops along the river with its vegetation mostly involving deciduous trees, bushes like sumac, as well as crops. In this piece, the predominant slope on the river side is between 30 to 70 percent mostly to the east and west. North and south slopes are normally more than 20 percent which increases on the heights. Natural homogenous piece in the valleys is comparatively narrow with granule landscape. The favorable visual cones from inside to the outside and vise versa (from the valley slope towards the city and the mountain range) are important. Moreover half-natural homogenous pieces contain crop, bush, and tree communities, having green spaces in residential complexes and green spaces along the roads. Dominant slope alongside the river is between 30 to 70 percent in east and west, with the north and south slope being normally between 7 to 20 percent. This piece possesses residential uses, dirt and tarmac access roads, and bridges. The valley is wider in this part, narrowing down towards the north. It has desirable inside to outside and vise versa (towards the city and the mountain range) views with high permeability and wide angle

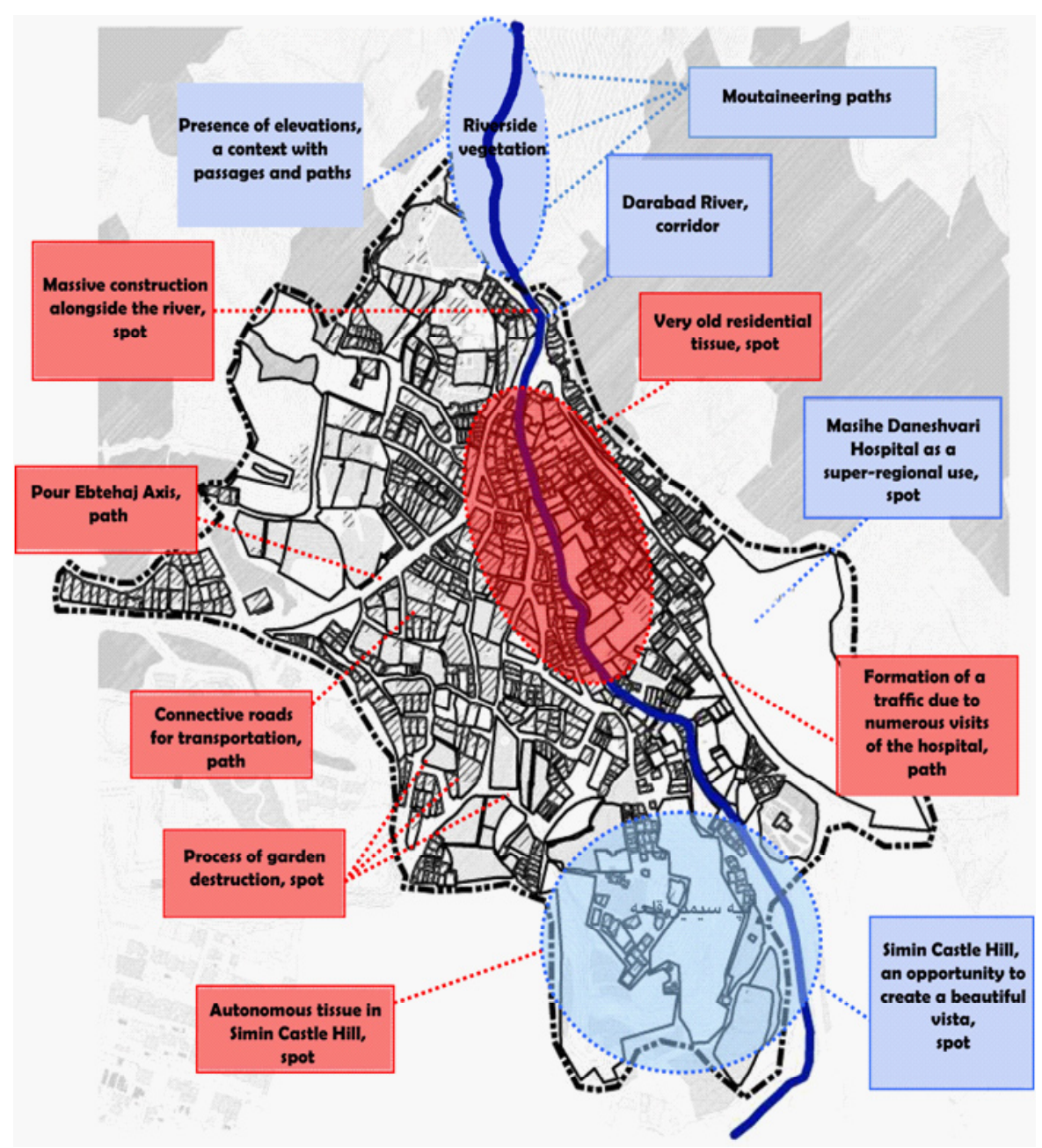

Picture. 1: Main elements of natural urban landscape of Darabad valley. Source: the authors 
of view. The vegetation in this piece is chiefly planted trees, including acicular and deciduous trees. On the other hand, fully-disturbed homogeneous piece has sparse vegetation by the riverside, mainly remaining from old gardens. In this piece arid lands along the river are patches, enabling a good view towards the river. This piece lacks any valuable vegetation both quantitatively and qualitatively and the outside to inside views vary from normal to poor. Yet because of mountainous landscape in its background there

Table 1: River valleys in urban landscape. Source: the authors with the help of various sources

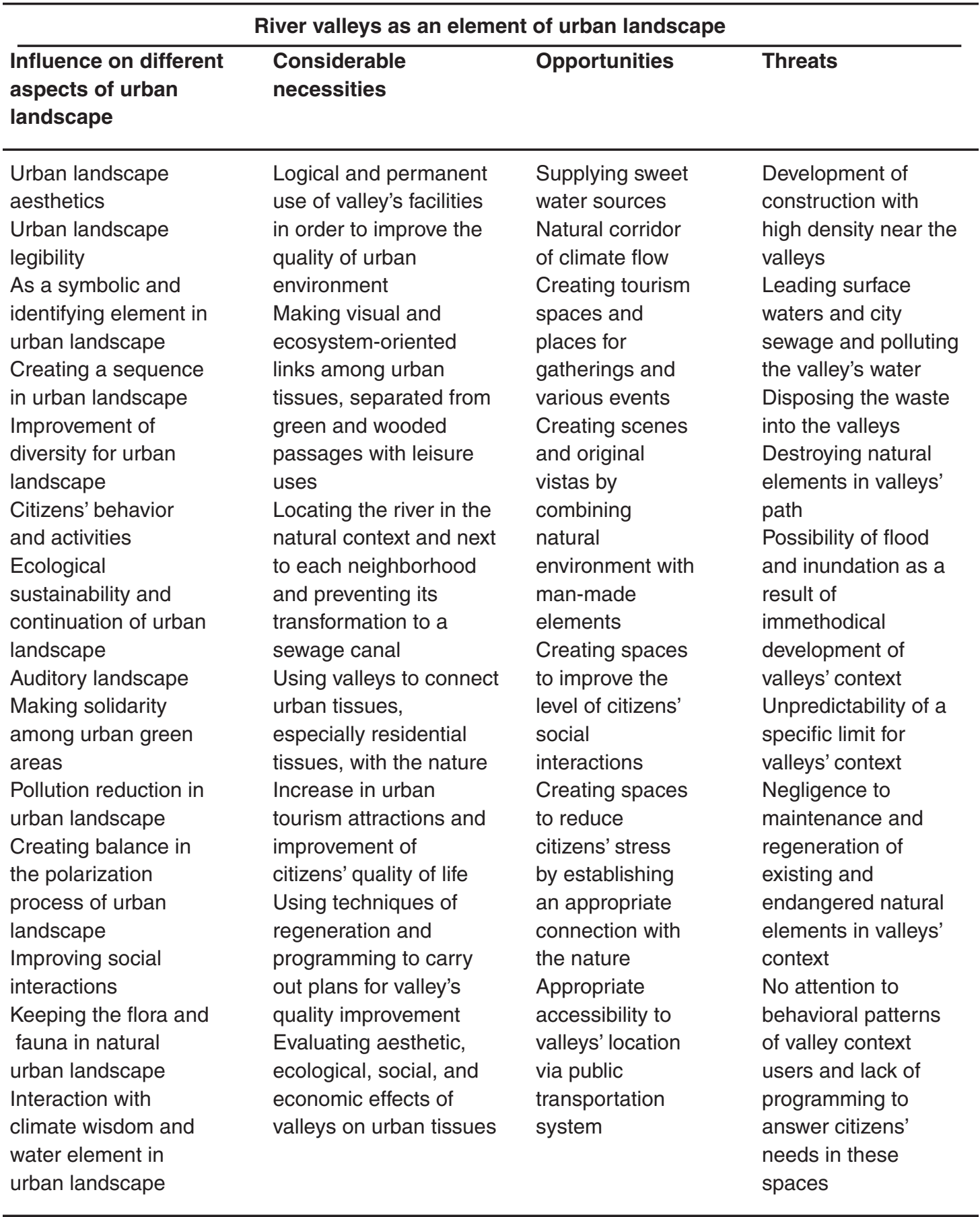


Table. 2: Main elements and components of ecological evaluation of urban natural landscape. Source: the authors by using (Bell, 1999)

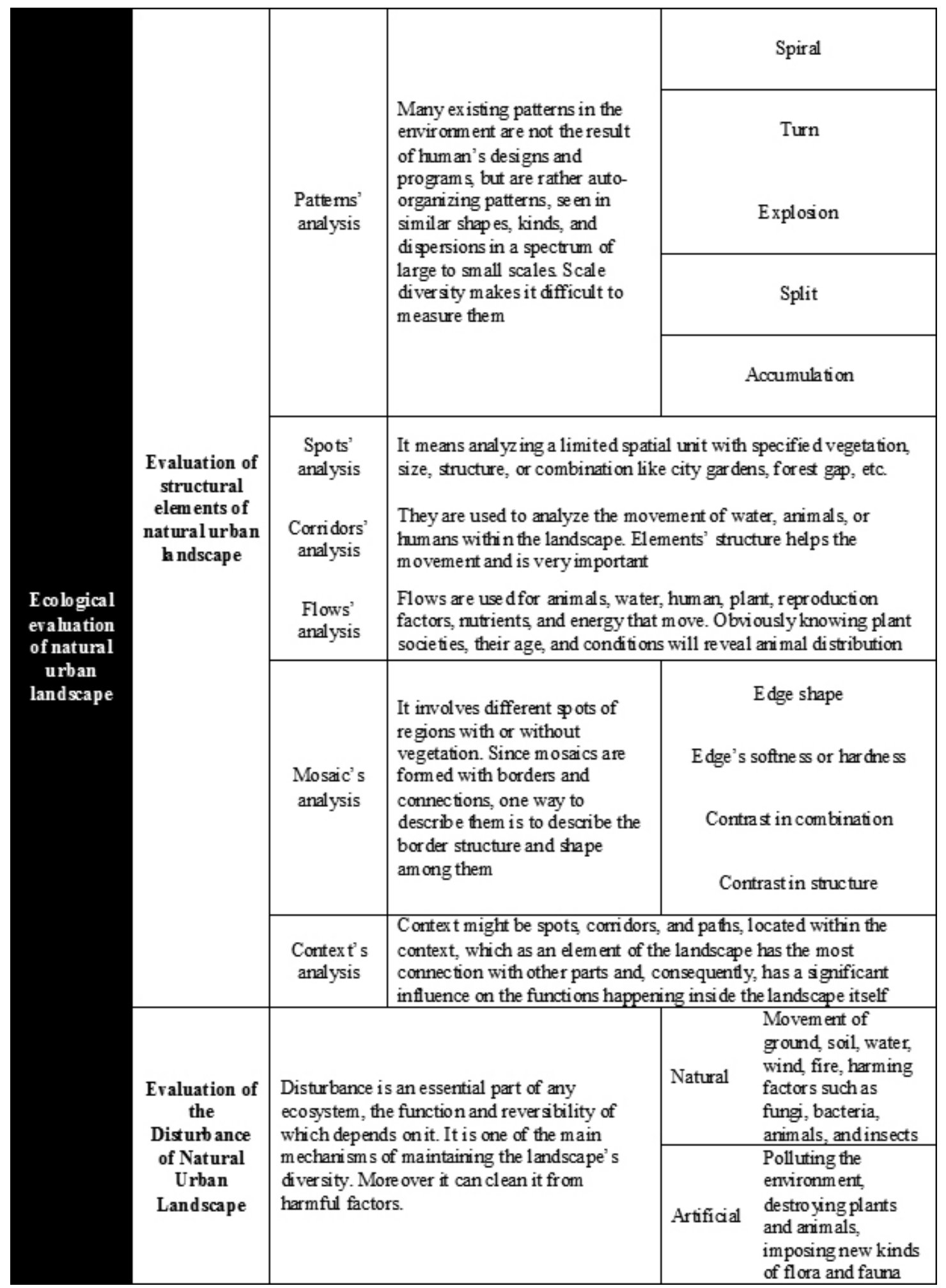


are wonderful inside to outside (towards north) views in some parts. Due to municipal waste and effluent from residential units, the river water in this piece is very polluted, having turned into a concrete canal in the south.

However in some parts of this natural context, buildings' advance to the edge of the river and valley has caused the opportunity of using the potential for tourism along side the river and the valley, and in some places even the opportunity for users' traffic, to decline so that currently the pavement alongside the river within the context faces numerous obstacles. Crossing the river in the upstream is only possible in two points and physical and visual connection between the two sides of the river special in the urban part seems to be weak. Furthermore despite attempts to reduce this problem, the river space in the natural urban patch has mostly turned into a space to dump the garbage and waste. Weak and damaged casing, over encroachment to the river limits, the downstream sedimentary that are gathered from crumbled tuffs, along with a possibility of slipping and landslide double the risk of flood-caused dangers. Table 4 analyzes the man-made and natural disturbances of the natural discourse of Darabad Valley (Table 4). Moreover, table 5 presents the ecological evaluation of the flow and structure of Darabad Valley (Table 5). In terms of qualitative improvement of environmental aesthetic experience in the river of Darabad Valley in accordance to the results from ecological evaluation

Table. 3: Ecological evaluation of the paths in natural urban landscape's mosaic of Darabad Valley. Source: the authors

\begin{tabular}{llll}
\hline $\begin{array}{l}\text { Main Natural } \\
\text { and Unnatural } \\
\text { Patches }\end{array}$ & $\begin{array}{l}\text { Pattern } \\
\text { Form }\end{array}$ & $\begin{array}{l}\text { Secondary } \\
\text { Natural and } \\
\text { Unnatural Patches }\end{array}$ & $\begin{array}{l}\text { River axis } \\
\text { Mountainous } \\
\text { - Natural }\end{array}$ \\
Half urban & $\begin{array}{l}\text { Side vegetation } \\
\text { - natural }\end{array}$ & $\begin{array}{l}\text { Mardens } \\
\text { Moving vehicle } \\
\text { paths }\end{array}$ \\
$\begin{array}{l}\text { Hiking and } \\
\text { pedestrian }\end{array}$ & $\begin{array}{l}\text { Pattern } \\
\text { Pure and untouched } \\
\text { spaces }\end{array}$ \\
Artificial (man-made) \\
residential patch
\end{tabular}


Table. 4: Analysis of the disturbances of Darabad Valley's natural context. Source: the authors

\begin{tabular}{|c|c|}
\hline Artificial disturbances & Natural disturbances \\
\hline $\begin{array}{l}\text { Existence of construction waste beside and } \\
\text { inside the river } \\
\text { Advance towards river limits and excessive } \\
\text { construction in the southern part without paying } \\
\text { attention to the dangers of landslide } \\
\text { General pollutions and liquid from pouring } \\
\text { house and hospital sewage and construction } \\
\text { waste disposal } \\
\text { Leaving solid and half solid waste into river bed } \\
\text { waters } \\
\text { Changing and destroying landform, plants, } \\
\text { environment, and landscape } \\
\text { Increasing process of destruction and changing } \\
\text { of mountainous and valley lands from north to } \\
\text { south } \\
\text { Presence of hunters who trap the animals } \\
\text { Turning river to canal and destroying riverside's } \\
\text { natural landscape in the southern part } \\
\text { Building insecure walls and foundations, which } \\
\text { are inharmonious to the natural landscape, and } \\
\text { destroying the natural margin of the river }\end{array}$ & $\begin{array}{l}\text { Existence of glacial and cold climatic } \\
\text { conditions in the winter, occurrence of heavy } \\
\text { rainfalls and blizzard, and possibility of } \\
\text { avalanche and frostbite } \\
\text { Weak rock structure, made of tuff, and creation } \\
\text { of much sediment in the river bed as a result } \\
\text { of erosion } \\
\text { Severe erosion of soil cover and debris in the } \\
\text { slopes due to lack of control over surface } \\
\text { Average to high water erosion and production } \\
\text { of average to high runoff } \\
\text { Natural limitations such as rock outcrops, soil } \\
\text { erosion, severe slopes, and low soil depth in } \\
\text { some parts of the area under study } \\
\text { Change in animals' eating habits and their } \\
\text { tendency to eat the garbage } \\
\text { Low vegetation diversity and their low } \\
\text { density in most of the area } \\
\text { Decrease in Darabad River's water discharge } \\
\text { since September until mid-autumn }\end{array}$ \\
\hline
\end{tabular}

Table. 5: Ecological evaluation of Darabad Valley's Flow and Structure. Source: the authors

\begin{tabular}{|c|c|c|c|}
\hline Structure & Water & Wild Life (Birds and Animals) & Human \\
\hline River Axis & $\begin{array}{l}\text { Reserving the water in } \\
\text { rainy seasons and freeing } \\
\text { it in rainless ones }\end{array}$ & $\begin{array}{l}\text { Settlement in cold seasons, } \\
\text { drinking water, feeding, } \\
\text { hunting }\end{array}$ & $\begin{array}{l}\text { Recreation and } \\
\text { diversion, river view, } \\
\text { walking alongside the } \\
\text { river }\end{array}$ \\
\hline $\begin{array}{l}\text { Riverside Trees } \\
\text { and Plants }\end{array}$ & $\begin{array}{l}\text { Decrease of erosion of } \\
\text { context's bed and frames } \\
\text { and keeping the region } \\
\text { moist as a result of } \\
\text { vaporizing }\end{array}$ & Nesting, feeding & $\begin{array}{l}\text { Using tree shades in } \\
\text { summers (creating a } \\
\text { pleasant space in } \\
\text { warm seasons) }\end{array}$ \\
\hline $\begin{array}{l}\text { Moving Paths for } \\
\text { Mountaineering }\end{array}$ & $\begin{array}{l}\text { Decrease of erosion and } \\
\text { keeping the region moist } \\
\text { as a result of vaporizing }\end{array}$ & Moving & $\begin{array}{l}\text { Transportation and } \\
\text { movement, doing } \\
\text { recreational and } \\
\text { athletic activities }\end{array}$ \\
\hline Man-made Patches & $\begin{array}{l}\text { Existence and pollution of } \\
\text { water and insertion of } \\
\text { sewage }\end{array}$ & $\begin{array}{l}\text { Presence and feeding from } \\
\text { human wastes }\end{array}$ & $\begin{array}{l}\text { Building residential } \\
\text { and service places }\end{array}$ \\
\hline
\end{tabular}




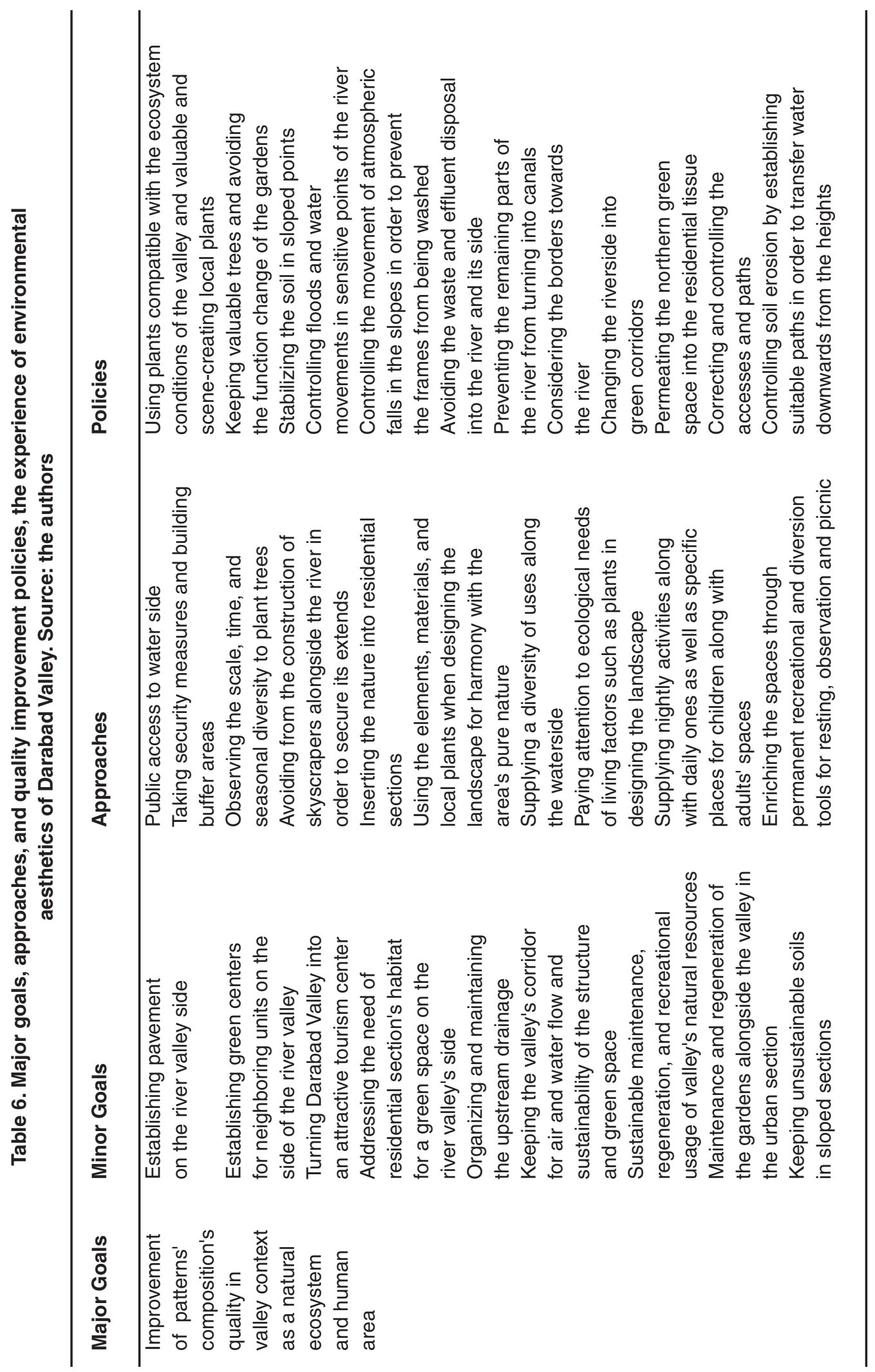




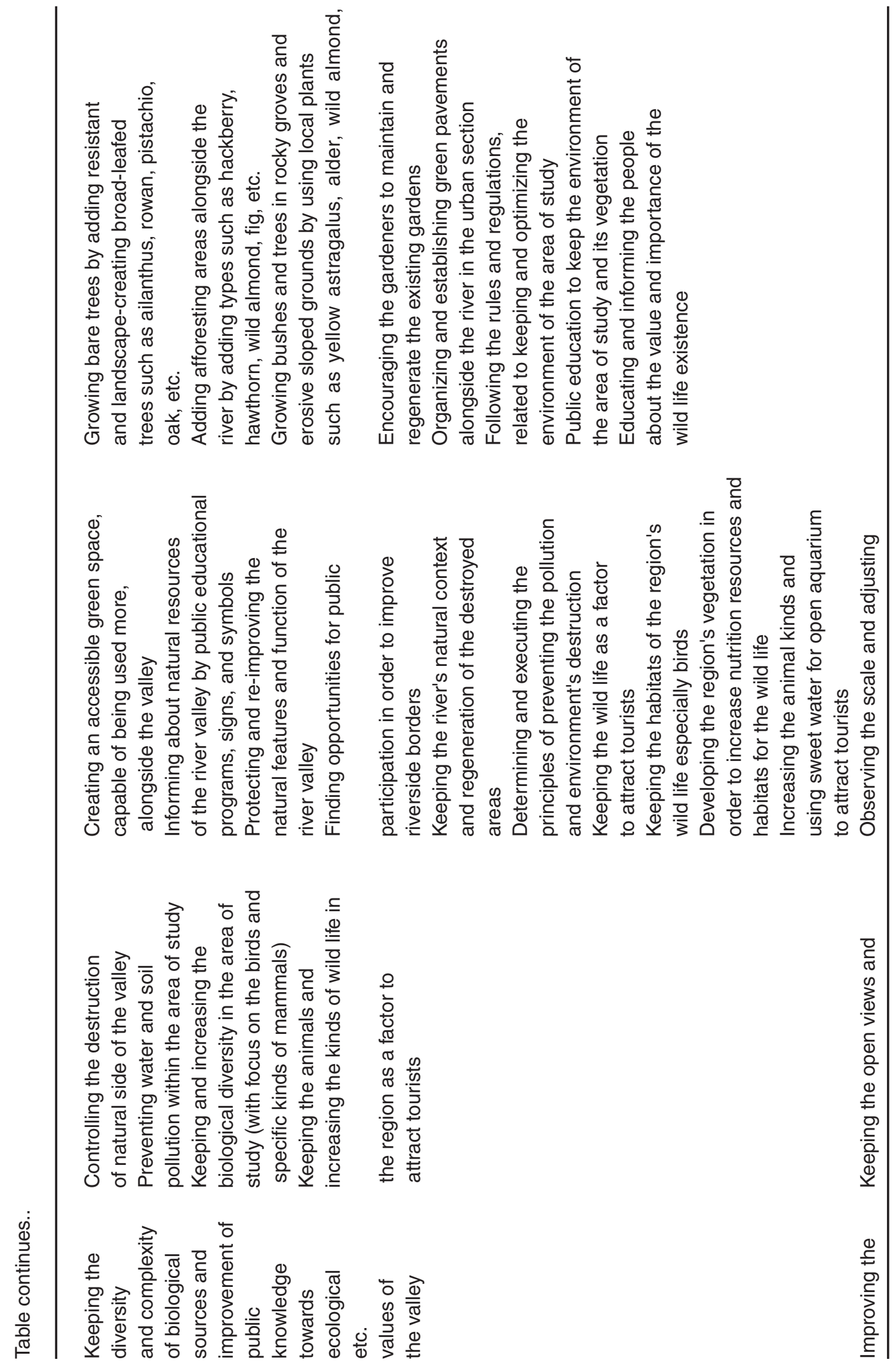




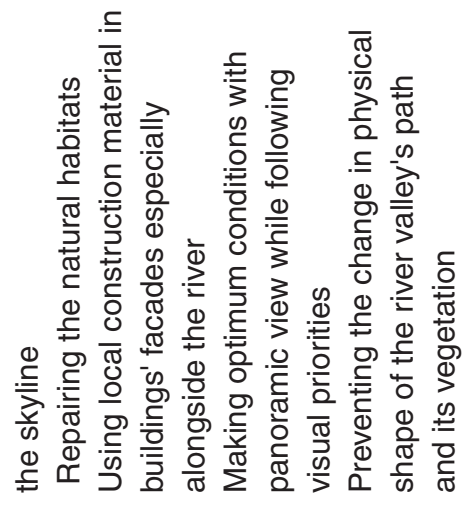

of natural context of this valley, it should be said that the presence of environmental pollutants (immethodical construction in the river's limit, usage of environmental pollutants, etc.) next to the river limits, the destruction of the vegetation next to the river bed, and the insertion of urban wastes and effluents into the river will bring about irrecoverable damages on the context's outstanding ecological values, decreasing the environmental quality of this natural urban landscape. Therefore, considering the mentioned disturbances, table 6 presents the approaches and policies, which conform to the natural patterns of the context to qualitatively improve the experience of environmental aesthetics (table 6).

\section{CONCLUSION}

Despite nature's ability to reconstruct herself after natural and artificial disturbances in addition to its resistance against the destruction of its ecosystems, nowadays mankind witnesses large-scale destruction of natural urban landscapes. Factors such as climate change, global warming, excessive exploitation of natural resources, human's greedy interferences in natural urban ecosystems such as forests, rivers, etc. have paved the way for pollution of vital water resources, soil erosion, and the collapse of genetic plant reserves of natural urban landscapes. The disturbance in such landscapes along with their large-scale destruction, happening as a result of human's lack of knowledge to the environment's nature and its within ecosystems, will bring difficulties for the conceptual-perceptual relation between human and nature in urban environments. That's why environmental aesthetics so reasons that if human intends to understand the importance of a serious experience of environmental aesthetics, he should know that the way to unlimited, pleasant, and creative understanding is to perceive the true essence of environment and nature. This attitude deepens human's imagination about the aesthetic experience, changing it from the process, initially imagined to be visual with instant pleasure, into a comprehensive thought in which all senses are used. The experience of environmental aesthetics in natural urban landscape starts with an understanding of beautiful parts of the environment (the minimum rate of beauty), ending with an understanding and perception of environment's abilities in terms of 
ecological health (the maximum rate of beauty). Therefore in an experience of environmental aesthetics there will be a connection with natural and cultural processes and patterns in order to discover their beauty. This connection involves human's basic understanding of the structure cycle of natural urban landscape. In fact if human can define natural urban landscape, determine his own position in it, and discern its processes he will have experienced the highest degree of environmental aesthetics. In this way knowing the complicated ecological layers and focusing on them will cause the landscape which human sees become more discernible. Accordingly this article introduced the ecological evaluation of the context as a method to focus more on the environment, know the ecological layers of natural urban landscape, and facilitate the pleasant experience of environmental aesthetics since ecological aesthetics of the context, being based on the theory of disturbance and complication, intends to know and understand the rules of growth and transformation of phenomena throughout the time so that it can present a more corehensive view with high flexibility towards the environment and its phenomena and patterns (figure 4). Thus an accurate identification of distinct ecosystem features as well as ecological analysis of the mosaic of the context's landscape requires qualitative improvement of the experience of environmental aesthetics in natural urban landscape. This is due to the fact that ecological evaluation and analysis of the landscape's mosaic along with the study and analysis of landscape's structural elements (patch, pathway, path, flow, etc.) the shaping form and the constituent patterns of these elements in the studied areas will make it possible to identify the changes in the rhythm of these patterns and by analyzing the landscapes' ecological health eventually enables having access to its current disturbances. By understanding these patterns and disturbances and by employing approaches and policies, related to the maintenance and regeneration of the patterns as well as omission and exclusion of the disturbances, it is possible to take influential steps for the qualitative improvement of the experience of environmental aesthetics in natural urban landscapes.

\section{ACKNOWLEDGEMENTS}

The research for this paper was financially supported by "Tehran Urban Planning and Research Center (TUPRC)". The Authors would like to thank them for their support.

\section{REFERENCES}

1. Chalmers, D. Environmental aesthetics: concepts and methods; pp. 23-48 in Proceedings of a Workshop on Environmental Perception. University of Otago, New Zealand, (1978).

2. Tuan, Y-F. Passing Strange and Wonderful: Aesthetics, Nature, and Culture. Washington, DC; Island Press, (1993).

3. Berleant, A. The Aesthetics of Environment. Philadelphia; Temple University Press, (1992).

4. Bourassa, S.C. The Aesthetics of Landscape. London; Belhaven, (1991).

5. Nasar, J.L. Environmental Aesthetics: Theory, Research and Applications. Cambridge; Cambridge University Press, (1992).

6. Punter, J.V. Landscape aesthetics: a synthesis and critique; pp. 100-23 in J.R.Gold and J.Burgess (eds) Valued Environments. London; Allen and Unwin, (1982)

7. Zube, E.H., J.L.Sell and G. Taylor Landscape perception: research, application and theory. Landscape Planning 9; 1-33., (1982).

8. Porteous, J.D. Environmental Aesthetics: Ideas, Politics and Planning, London, Routledge, (1996).

9. Bell, S. Landscape: Pattern, Perception, and Process, London: E \& FN Spon Press, (1999).

10. Parhas et al. Framework of Urban Designing of Abbas Abad Lands, Nosazi Abbas Abbad Office, 2004. [In Persian]

11. Yavari A. et al. Correction of Ecological Structure and Environmental Function of Urban Region, Case of Study: Natural Corridors of River valleys in the Capital, Collection of articles from the first seminar of Constrcution, Sabeghoon Publictaion: Tehran, 2004. [In Persian]

12. Behbahani I., Shafiei H. and Shafiei B. Mountain Landscaping by Using Local Plants; Ecological Scientific research Journal, 42, 
2007. [In Persian]

13. Farina, A. Principles and Methods in Landscape Ecology Towards a Science of Landscape. Netherland: Springer, (2007).

14. Fernandes, J. Landscape ecology and conservation management Evaluation of alternatives in a highway EIA process. Environmental Impact Assessment Review 20. Pp 665-680, (2000).

15. Rose, M.C. Nature as an aesthetic object: an essay in meta-aesthetics. British Journal of
Aesthetics 16; 3-12, (1976).

16. Seamon D. The Phenomenological Contribution to Environmental Psychology, Journal of environmental psychology, 2; 119140, (1982).

17. Smardon R. Perception and aesthetics of urban environment, Landscape and Urban planning 15; 85-106, (1988).

18. Thorne, J. landscape ecology: a fountain for greenway design. minneapolis: university of minnesota. (1993). 